\title{
Small Scale Gasification of Biomass and Municipal Wastes for Heat and Electricity Production using HTAG Technology
}

\author{
Jan Stasiek $^{1, *}$, Marcin Jewartowski ${ }^{1}$, and Weihong Yang ${ }^{2}$ \\ ${ }^{1}$ Gdansk University of Technology, Faculty of Mechanical Engineering, Dep. of Energy and Industrial Apparatus, \\ ul. G. Narutowicza 11/12, 80-233 Gdansk, Poland \\ ${ }^{2}$ Royal Institute of Technology, Department of Materials Science and Engineering, Div. of Energy and Furnace Technology, \\ Brinellvägen 23, S-100 44 Stockholm, Sweden
}

\begin{abstract}
Combustion and gasification technology utilizing high-cycle regenerative air/steam preheater has drawn increased attention in many application areas. The process is to be realized at temperature level above ash melting point using highly preheated agent. The use of highly preheated media above $900^{\circ} \mathrm{C}$ provides additional energy to conversion processes and results in considerable changes to the design of combustion and gasification equipment and its performance. This paper presents an advanced gasification system that utilizes high-temperature air and steam to convert biomass and municipal wastes into syngas production as well as selected results from experimental studies of high temperature air/steam gasification.
\end{abstract}

\section{Introduction}

Biomass is an organic material coming from living organisms and does not add carbon dioxide to the environment. It can be used as a source of energy and is one of the most commonly used fuels around the world and can be good supplement or even alternative for fossil fuels due to increasing demand for energy. It can be directly burned or converted into fuel trough pyrolysis or gasification and used to generate heat or electricity. Most of biomass can be converted by gasification and the process is generally more efficient than direct combustion. The value of a biomass depends on the chemical and physical properties of the large molecules from which it is made [1]. The product of gasification has lower heating value compared to fossil fuels but can be used in similar power plants for heat and electricity production.

The automotive industry generates yearly millions tones of wastes. Many components are recovered, but remaining parts are mechanically processed automotive shredder residue (ASR). It is a complex mixture of materials, which may be toxic. Combustion is used commonly for its utilization, however it has disadvantages, and pollutant emission is the one, which has to be considered. Therefore, pyrolysis and/or gasification are more promising methods of ASR utilization and generation of energy [2]. Municipal solid wastes (MSW), associated with nonindustrial human activity, are continually generated in large amounts around the world, creating problems with their disposal. Also here, gasification is the technique, which provides better solution to a problem than incineration technology [3].

In biomass gasification, the fuel gas can contain significant amounts of tar, formation of which can be suppressed by high temperature or additionally decomposition can be expected by thermal cracking and steam reforming. Tars can be also eliminated by the use of a catalyst. However tar behavior must be further investigated in order to meet requirements of acceptable tar content, less than $100 \mathrm{mg} / \mathrm{Nm}^{3}$ for satisfactory internal combustion engine operation.

\section{High Temperature Air/Steam Gasification}

The use of biomass and wastes for energy production is a subject of many ongoing research and development projects. There are at least four main methods of biomass and waste utilization: direct combustion, pyrolysis, biodegradations and gasification. Direct combustion of biomass or wastes is not acceptable due to different pyrolysis and oxidative pyrolysis time for the various materials present in the stream of the fuel. The gasification process converts raw biomass into a combustible gas, with energy content within the region of $60-70 \%$ of the original biomass feedstock. This gas can then be burnt to produce thermal energy, or to run engines for mechanical or electrical power. Gasification is the incomplete combustion of solid biomass forming a mixture of gases referred to as Fuel Gas. Carbon monoxide is the predominant component of useful heat value. Other gaseous products depend on whether the conversion is achieved with air or pure oxygen, whether water is introduced into the feedstock and the temperatures reached in the process. Hydrogen will be produced if water is present and temperature in excess of $900^{\circ} \mathrm{C}$ is reached. Excess water will permit the creation of carbon dioxide which will weaken the heating value of the mix. Air facilitates a low temperature conversion,

\footnotetext{
* Corresponding author: jstasiek@pg.gda.pl
} 
however a low heat value gas will be created as nitrogen will be present in the final mix. Fuel gas has a relatively low heat value $\left(4-11 \mathrm{MJ} / \mathrm{Nm}^{3}\right)$ and is therefore best used in situ for heating or power generation.

Gasification can be made with air or steam as a gasification media. Air gasification for heat and power production is the most common technology developed and applied. Much less developed is technology for the synthetic fuels (syngas) production from biomass and wastes. Users expect technology, which can transfer whole solid waste fuel to clean fuel gas. Therefore production of tar, soot and char should be minimal or ideally prevented. In general, gasification could be divided into two processes according to the temperature of the feed gas (gasification agent):

- low temperature gasification - where cold or slightly preheated air is used as gasifying agent,

- $\quad$ high temperature gasification, which air preheated or mixture of air and steam preheated above $1000^{\circ} \mathrm{C}$ is used as gasifying agent (Fig. 1).

\section{Conventional}

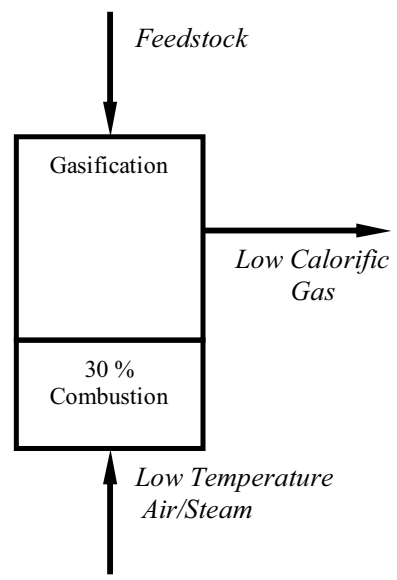

HTAG

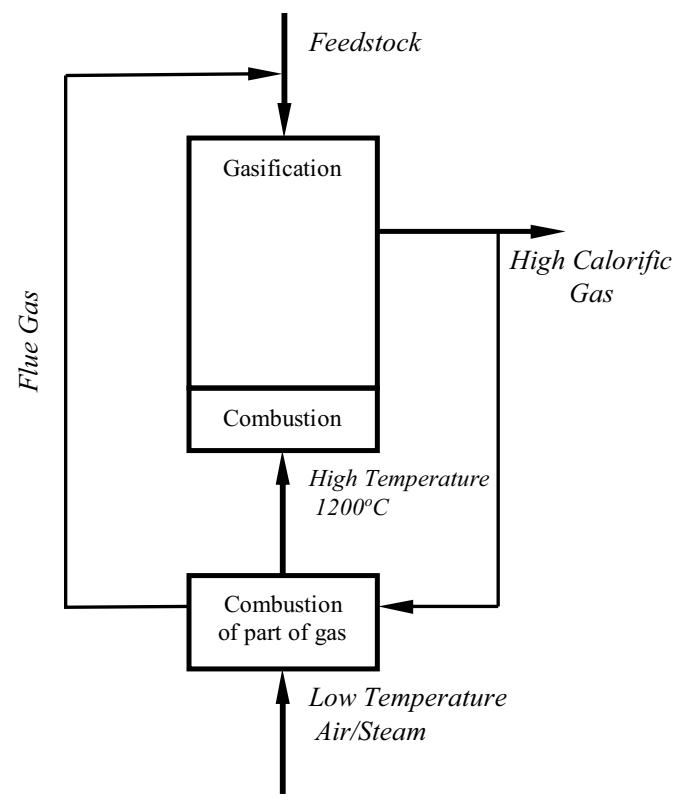

Fig. 1. Comparison between conventional and HTAG gasification
Low temperature combustion processes (grate combustion, fluidized bed combustion or gasification) will have difficulties to fulfill new European Community regulations, particularly regarding ash residues, which cannot be landfilled in the nearest future. Also it is important to stress that using the low-temperature processes is the most common to produce only heat in a form of hot water or steam. What is needed is the product, which can be used freely. This is fuel gas from biomass or wastes (syngas), which can then be used in boilers (for example as reburning gas to reduce NOx), in industrial furnaces as a substitute of natural gas or mixed with natural gas, in gas turbines, chemical plants and last but not least for small scale production of electricity using the internal gas combustion engines, gas turbines or fuel cells.

Research and Development on High Temperature Air Combustion (HiTAC) of gas and liquid fuels is followed by development of a new gasification processes with high temperature air and steam called High Temperature Air/Steam Gasification (HTAG or HiTAG). This new technology has been applied in performing extensive studies on thermal conversion of biomass and wastes into fuel gas, since year 2001 at Royal Institute of Technology (KTH) [4-6]. It uses high-cycle regenerative air/steam preheater developed by Nippon Furnace Kogyo Kaisha Ltd. to convert biomass and municipal wastes into hydrogen-rich fuel gas (Fig. 2). The generator allows preheating of air or mixture of air and steam up to $1300^{\circ} \mathrm{C}$. High temperature gasification is carried out with air or steam as a gasification agent (feed gas).

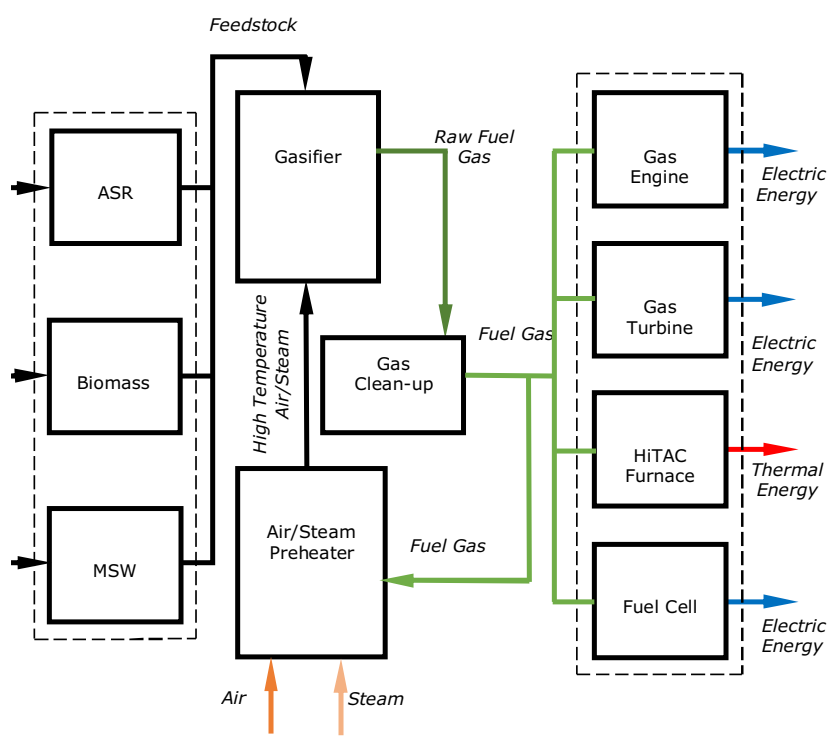

Fig. 2. General scheme of HTAG plant for different utilization alternatives of the syngas (fuel gas) from biomass and wastes

Using highly preheated air or mixture of air and steam changes energy balance of the gasifier and phenomena of gasification process. Less feedstock is burned thus less flue gas is produced what results in less diluted fuel gas. Calorific value of the fuel gas from high temperature air/steam gasification is much higher comparing to any low temperature air gasification process. In case of dry biomass it is normally above 
$8 \mathrm{MJ} / \mathrm{Nm}^{3}$ in case of high temperature air/steam gasification. Since pyrolysis and char residue gasification is carried out at much higher temperature the tar is already decomposed in much higher degree. It results thus in much lower contamination of the fuel gas with tar and dust. Gasification of high calorific wastes (as plastics, rubber or automotive shredder residues) with high temperature air and steam results in much higher calorific value of the fuel gas compared to gasification of low calorific wastes. Produced fuel gas can be used in many applications for example to produce electricity in gas engine, gas turbine or in near future, even in solid fuel cell.

The main features of the HTAG process in converting biomass and wastes to fuel gas are:

- conversion of solid wastes and low grade fuels to clean gaseous fuels,

- $\quad$ high calorific value and high amounts of hydrogen and hydrocarbons in the composition of fuel gas,

- high efficiency of conversion from solid to gas fuel,

- no landfilling of ash residues is required,

- minimum amount of pollutions generated,

- $\quad$ high intensity of process (conversion rate).

\subsection{Gasifier system}

Investigations on HTAG in KTH were performed initially using batch type downdraft fixed-bed gasifier [5] following by continuous downdraft one, which was later transformed into updraft-type gasifier. Fig. 3 presents concept of an advanced HTAG installation in view of fuel gas (syngas) production. The fuel was fed from the top of the reactor using continuous feeding system.

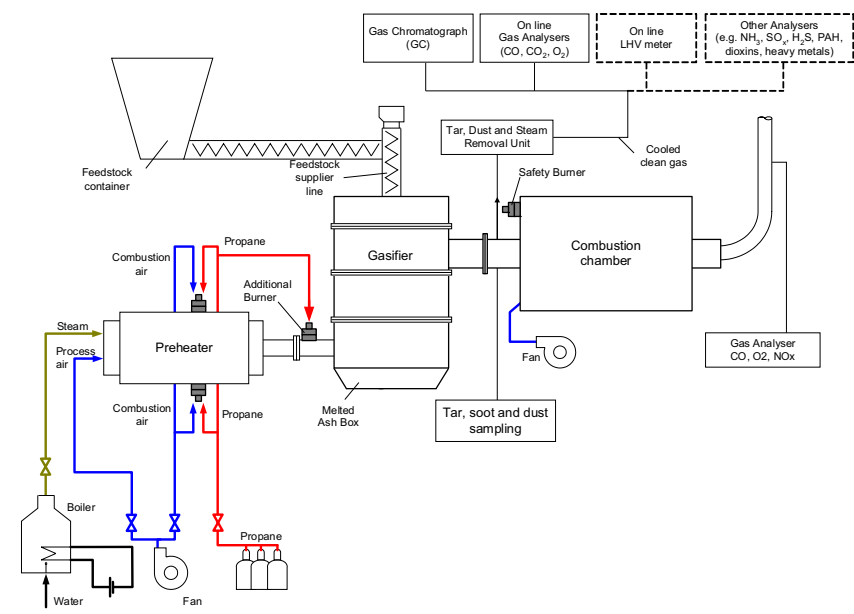

Fig. 3. General scheme of HTAG system with continuous gasifier

\subsection{Selected results of HTAG Investigations}

Results of wood pellets gasification with HTAG show, that highest concentration of desired gaseous products (hydrogen, carbon monoxide and methane) in produced syngas can be achieved only with steam as gasifying agent. The steam controls the gasification temperature, if the preheated air and steam mixture is used [5,7]. The gasification temperature response to the change of the feed gas composition and temperature of the feed gas is also discussed. The results showed that the use of steam in the feed gas decreases the process temperature sharply. Increase of the feed gas temperature reduces production of tars, soot and char residue as well as increases the heating value of the dry fuel gas produced, (Fig. 4 and 5) [8]. Results of mathematical modelling of gasification using high-temperature air show, that increase of the feed gas temperature results in a higher gasification rate, higher molar fractions of $\mathrm{H}_{2}, \mathrm{CO}$ and $\mathrm{C}_{\mathrm{m}} \mathrm{H}_{\mathrm{n}}$, hence higher LHV and a faster ignition rate [4].

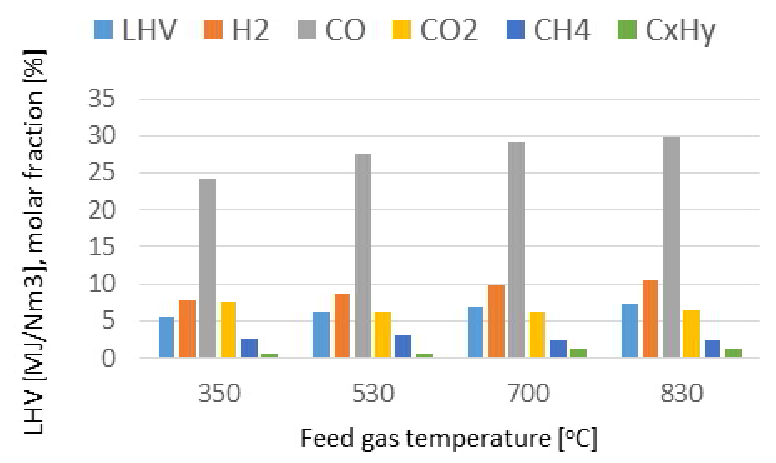

Fig. 4. Influence of the temperature of the feed gas on the average values of LHV and composition of dry fuel gas for HTAG of wood pellets: feedstock - wood pellets $12 \mathrm{~mm}$, feed gas flow $-50 \mathrm{Nm}^{3} / \mathrm{h}$, fuel mass $-20 \mathrm{~kg}, \mathrm{X}_{\mathrm{H} 20}: 0 \%$.

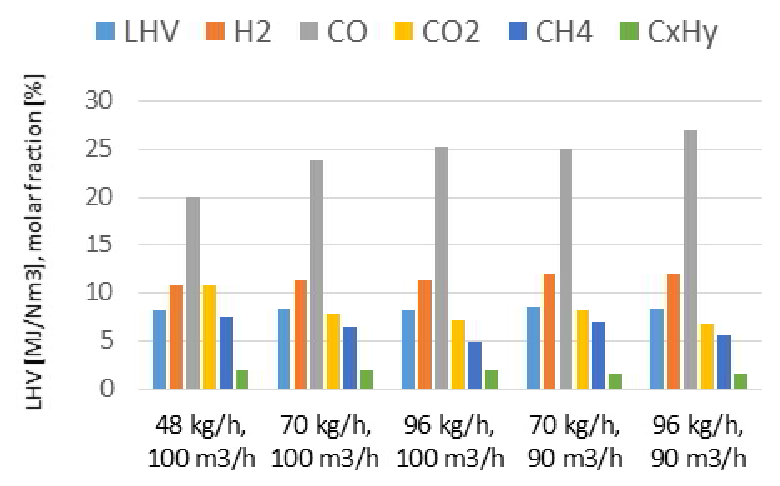

Fig. 5. Composition of produced fuel gas, its temperature and LHV for different continuous gasification conditions of wood pellets: different pellets flow $[\mathrm{kg} / \mathrm{h}]$, oxidizer flow $[\mathrm{m} 3 / \mathrm{h}]$ and process temperature (from left to right: $810^{\circ} \mathrm{C}, 586^{\circ} \mathrm{C}, 431^{\circ} \mathrm{C}$, $\left.654^{\circ} \mathrm{C}, 415^{\circ} \mathrm{C}\right)$.

The high temperature air/steam gasification technique has been tested for a fuel in pellet form made from waste material of woody and plastic origin. The feedstock was gasified in an updraft fixed bed reactor by mixtures of air and steam ( $4 \%$ to $82 \%$ steam) preheated to $1400^{\circ} \mathrm{C}$, a temperature well above the fluid temperature of the feedstock. HTAG was reported as a good way of utilizing plastic containing fuel [9]. This technology was also used in experimental studies that were conducted using tropical coffee husks under high temperature conditions [10]. It was found the positive influence of high temperature on increasing the gasification process. Increased gasification temperature 
led to a linear increment of $\mathrm{CO}$ concentration in the syngas.

The use of HTAG has been proposed for two-staged method of ASR treatment [11]. ASR was primarily treated by microwave pyrolysis and later the liquid and solid products become the feedstock for the high temperature gasification process. Concept was proposed to maximize the conversion of organic contents of ASR into valuable products, while preserving metals during each step of the process. Results of experiments conducted in a batch-type, lab-scale gasifier using high temperature steam show that HTAG can be used as the complimentary method to pyrolysis and in particular microwave pyrolysis. Further investigation using two different types of gasifying agent: pure steam and $3 \%$ of oxygen at temperature between $700^{\circ} \mathrm{C}$ and $950^{\circ} \mathrm{C}$ show that two undesirable phenomena occurred: with increasing temperature of the process the reaction rate decreases and there was no significant differences between steam and oxygen gasification rates. That indicates, that increasing the temperature of reaction is not always the best option to improve the gasification process and increase its rate, since this is not the only effect influencing the process performance [12].

\section{Conclusions}

High Temperature Air/Steam Gasification proved to be very useful technology for gas fuel generation, which can be used later to produce heat and electricity. HTAG is applicable to biomass gasification as well as to treatment of municipal wastes and automotive shredder residue and successfully converting its energy into heat and/or electricity.

\section{Acknowledgement}

The work reported in this paper includes scientific cooperation between Gdansk University of Technology (GUT), Poland and Royal Institute of Technology (KTH), Stockholm, Sweden. The personal assistance of Professor Wlodzimierz Blasiak and his help in experimental performance is kindly acknowledged.

\section{References}

1. P. McKendry, Bioresource Technol. 83, 37-46 (2002)

2. P. Donaj, W. Blasiak, W. Yang, C. Forsgren, Journal of Hazardous Materials 185, 472-481 (2011)

3. C. Zhou, T. Stuermer, R. Gunarathne, W. Yang, W. Blasiak, Fuel 122, 36-46 (2014)

4. W. Yang, A. Ponzio, C. Lucas, W. Blasiak, Fuel Processing Technology 87, 235-245 (2006)

5. W. Blasiak, S. Kalisz, D. Szewczyk, C. Lucas, R. Abeyweera, High Temperature Air/steam Gasification of Biomass and Wastes - Stage 2, Technical Report No.2, ISRN KTH/MSE-03/61SE+ENERGY/TR, Royal Institute of Technology, Stockholm, Sweden, (2003)
6. A. Ponzio, W. Yang, W. Blasiak, J. Stasiek, Hydrogen generation from biomass using high temperature agent gasification from biomass using high temperature agent gasification, 16th European Biomass Conference and Exibition, Feria Valencia, Spain, 2-6 June (2008)

7. D. Mikielewicz, J. Stasiek, W. Blasiak, A. Ponzio, W. Yang, Advanced Technology for Thermochemical Conversion of Biomass and Solid Muncipial Wastes for Hydrogen-Rich Gas Production, 8th European Converence on Industrial Furnaces and Boilers, Vilamura, Portugal, 25-28 March, (2008)

8. C. Lucas, D. Szewczyk, W. Blasiak, S. Mochida, Biomass and Bioenergy 27, 563-575 (2004)

9. A. Ponzio, S. Kalisz, W. Blasiak, Fuel Processing Technology 87, 223-233 (2006)

10. L. Wilson, G.R. John, C.F. Mhilu, W. Yang, W. Blasiak, Fuel Processing Technology 91, 13301337 (2010)

11. P. Donaj, W. Yang, W. Blasiak, C. Forsgren, Journal of Hazardous Materials 182, 80-89 (2010)

12. P. Donaj, W. Yang, W. Blasiak, C. Forsgren, Journal of Hazardous Materials 185, 472-481 (2011) 